\title{
NEOLIBERALISMO Y MOVILIZACIÓN CIUDADANA: DOS ESLABONES PERDIDOS EN LA COMPRENSIÓN DE LA CRISIS DE DERECHOS HUMANOS EN MÉXICO
}

\section{Diana Favela-Gavia ${ }^{1}$}

\section{Resumen}

Este ensayo se propone examinar la crisis de los derechos humanos que afecta a la sociedad mexicana, recuperando la importancia de dos factores ignorados por la literatura del campo: la incidencia de la estrategia neoliberal y el incremento de la movilización social. La situación de los derechos humanos en regímenes en transición y bajo el impacto de las políticas de apertura y privatización se deterioran en la medida en que las élites políticas enfrentan el desafío de la movilización social mediante el recurso a la represión. Concurrentemente, el estancamiento, la polarización, la concentración de la riqueza y el crimen organizado juegan un papel central en esta explicación de la crisis de los derechos humanos en el México contemporáneo.

Palabras-clave: Derechos Humanos, Movilización social, Transición democrática, Violencia de Estado.

\section{INTRODUCCIÓN}

La situación de los derechos humanos en México es realmente dramática. Dada su gravedad es un tema presente en diversos ámbitos: diarios, informes de ONGs, de organismos internacionales e incluso de entidades gubernamentales mexicanas. A pesar de ello no abundan los intentos de explicar de manera cabal el problema. El predominio de los enfoques jurídicos en el estudio del tema lo mantiene confinado a enfoques tradicionalistas (Estévez 2010) y aunque los abordajes desde las ciencias sociales se han multiplicado en los años recientes, siguen siendo insuficientes. Esta interpretación plantea que esta crisis resulta no solo de deficiencias legales, omisiones involuntarias o conductas veleidosas, sino de la contraposición entre, por un lado, los intentos de los grupos subalternos para revertir el deterioro de sus condiciones de vida y trabajo, así como el despojo de sus derechos y recursos, y por el otro, la decisión del grupo en el poder de retener el control del aparato estatal, y hacer frente al descontento social, recurriendo a la violencia de Estado. Retener el control del aparato estatal resulta hoy más que nunca crucial para mantener las políticas neoliberales (Meiksins 2000 y Harvey 2004) en un contexto de guerra contra las drogas, que justifica las violaciones. El ensayo tiene dos partes. La primera presenta los enfoques sobre el

\footnotetext{
${ }^{1}$ Doctora en Ciencia Política, Universidad de Tulane, USA. Investigadora titular B da Universidad Nacional Autónoma de México - UNAM. E-mail: 2014mf02@gmail.com
} 
problema y la hipótesis del trabajo: la concurrencia entre el incremento de la movilización social -incentivada por las consecuencias del neoliberalismo- y el aumento en las violaciones de DH en México. La segunda argumenta el papel que el Estado juega en el modelo neoliberal, su incidencia en el deterioro económico, el aumento de la delincuencia y en la violación de los derechos humanos en México. En las conclusiones se pondera el potencial explicativo de la interpretación presentada.

\section{MOVILIZACIÓN SOCIAL Y VIOLACIÓN DE DERECHOS HUMANOS: MÁS MUERTES EN LA TRANSICIÓN}

En el examen de los derechos humanos en México predominan los enfoques jurídicos (Estévez 2010), pero los enfoques desde las ciencias sociales se han multiplicado: unos abordan los cambios en la política de derechos humanos usando modelos teóricos (bumerang y espiral) sobre la articulación entre actores internos y externos, en general (Keck y Sikkink 1999, 2000; Anaya 2009, 2012), o en áreas específicas (Staudt y Coronado 2007, Aikin 2011). Otros señalan el abismo entre la dimensión formal y las conductas reales (Moloeznic 2007 y Huber 2009) mostrando que la política de derechos humanos en México es declarativa y no una política de Estado. Maza (2009) afirma que la "institucionalización" desactivó la presión internacional y permitió el uso retórico que revirtió el proceso. Treviño (2014) muestra incluso que desde el ámbito legal se frenó el cambio y se usó el discurso de los derechos humanos para legitimar los abusos. Por otro lado, Hincapié (2015) desde la perspectiva de los "ordenamientos mixtos" subraya la expansión del crimen organizado, que en un contexto de reformas estatales y conflictos sociales, lo convierte en agente regulador de las acciones colectivas, con las consecuencias previsibles en los derechos humanos.

Estos aportes amplían la comprensión del problema, sin embargo dejan al menos dos cabos sueltos: por un lado, la creciente movilización social y por otro, el impacto de la estrategia neoliberal: ambos juegan un papel central en la presente crisis de los derechos humanos en México. En la perspectiva que proponemos, la activación ciudadana de grandes grupos de población, involucrados en la defensa de sus recursos y atribuciones cercenados por el proyecto neoliberal, en un contexto de transición política, es respondida con violaciones a los derechos humanos por una elite comprometida en mantener a toda costa la política privatizadora y aperturista, generadora de desigualdad extrema y de mayor conflictividad social.

Aceptando que democracia es sinónimo de respeto a los derechos humanos, tradicionalmente se suponía que la transición hacia la primera implicaba la inmediato mejora de los últimos (Davenport 1995). Sin embargo, algunos autores mostraron que en el ínterin la incidencia de violaciones era incluso mayor que en los regímenes abiertamente no democráticos. Se elaboró entonces la tesis MM (More Murder in the Middle) (Fein 
1995 y King 1998) según la cual, la mayor violación de los derechos resulta de que: (1) la parcial apertura del sistema político proporciona, a grupos previamente excluidos, la posibilidad de movilizarse para mudar "el orden político y distributivo"; (2) los estados "en transición" se abren suficientemente para permitir las expresiones públicas de disenso, pero no bastante para aliviar las causas de la insatisfacción, por lo que las demandas de los ciudadanos aumentan y, dada la falta de canales institucionales, se expresan como acción colectiva contenciosa; (3) la incoherencia institucional, se fragilizan ante la movilización social y las élites, temiendo la revuelta popular y el derrocamiento político, responden con represión a los desafíos (Reagan y Henderson 2002).

Esta tesis se funda en la percatación de que no hay una relación unívoca entre instituciones y prácticas políticas, pues mientras el cambio institucional puede ir en el sentido de la democratización (que de esta suerte se transforma en mera liberalización política), las conductas desplegadas por los grupos que detentan el poder revelan la abierta resistencia a seguir el mismo rumbo, acentuando el recurso a la violencia como medio de control social, generando violaciones masivas de derechos humanos. Tenemos entonces que la creciente movilización social, incentivada por los daños en las condiciones materiales de vida y los cambios alcanzados en el orden institucional, se enfrenta a una respuesta autoritaria y violenta de las élites para mantenerse en el poder.

\section{CRECIMIENTO DE LA MOVILIZACIÓN SOCIAL}

Es notorio que la acción colectiva se ha intensificado a lo largo de los últimos veinte años en los más diversos frentes de la sociedad mexicana. Por un lado, el agudo deterioro de las condiciones de vida y trabajo que afectan de manera generalizada a amplias capas de la población, las ha impulsado a organizarse. Por otro lado, la movilización contenciosa muestra que el proceso de liberalización política, a pesar de los cambios logrados, no satisface los reclamos de participación, empujando a la ciudadanía a la movilización por medios no convencionales. La intensificación de la acción ciudadana la acusa el reporte de SERAPAZ "Criminalización de la protesta" (Romo 2008) que señala que en 2007 se registraron más de 900 conflictos sociales, en tanto en 2006 habían sido 432 (Centro Pro, 2006:174). Este crecimiento de las expresiones de inconformidad social a medida que se abre el sistema político resultan, como lo señaló Eisinger (1973), del hecho de que las expectativas democratizadoras de la ciudadanía superan con mucho los grados de apertura del régimen.

La constatación de esto lo encontramos en las expresiones de los ciudadanos movilizados como sustento de su posicionamiento y de su rechazo a las decisiones gubernamentales, al decir que el gobierno los atropella al "no tomarlos en cuenta"; como claramente afirmó una habitante de Atenco: "Todos los días en la televisión hablan de democracia. ¿Y eso es el hacer un aeropuerto sin peguntarle a la gente? ¿Es esa la democracia?"(Rodríguez Nieto 2001) 
Si revisamos las movilizaciones de los años recientes, vemos cómo se ha acentuado la articulación del contenido reivindicativo material de las luchas, con la exigencia de respeto a los derechos sociales, como freno a los embates cada vez más intensos y amplios de las políticas neoliberales del capitalismo globalizado que despoja de derechos y de recursos, económicos, naturales, incluso simbólicos, a individuos y comunidades. Las reivindicaciones planteadas van desde la obtención y reconocimiento legal de la propiedad de la tierra -rural y urbana-, apoyos para la producción y comercialización de bienes; retención de puestos de trabajo, contra la precarización laboral y por el mejoramiento de los servicios públicos, así como por impedir el despojo de recursos, espacios y derechos ganados previamente: pensiones, educación pública, atención médica, tierras comunales, agua, etc. (Favela 2010a).

En este proceso se va construyendo ciudadanía: luchas cuyo detonante inicial era meramente defensivo, van dando paso a vindicaciones cívico-políticas que enarbolan derechos ciudadanos, redefinen sus objetivos y sus alcances, hasta no sólo cuestionar el carácter excluyente de las políticas públicas que integran el proyecto de desarrollo neoliberal, sino brindar propuestas alternativas al mismo².

A partir de 1994, las principales movilizaciones sociales, orientadas por beneficios materiales, han demandado mejoras salariales, freno a despidos y recorte de personal, apoyo a la producción agrícola afectada por la apertura comercial, y protección de recursos naturales amenazados por proyectos hidroeléctricos, mineros y aeroportuarios: Coordinadora Nacional de Trabajadores de la Educación (CNTE), Asamblea Popular de los Pueblos de Oaxaca (APPO), La Parota, Atenco, El Campo no Aguanta más, Frente en Defensa de Wirikuta y Minera San Javier, entre las más visibles. Por su número ${ }^{3}$ y carácter destacan los conflictos mineros, que articulan tres dinámicas: primero, el interés particular de capitales (nacionales y extranjeros) por explotar recursos ubicados en terrenos de propiedad comunal (muchas veces tierras sagradas) ${ }^{4}$; segundo, la conducta de los servidores públicos que autorizan operaciones que causan severos daños ambientales; y tercero, cuando se manifiesta la oposición a estas operaciones, empresas y autoridades, reaccionan con violencia ${ }^{5}$, poniendo por encima del

\footnotetext{
${ }^{2}$ La ENCUP revela que los entrevistados había participado en alguna acción colectiva pasaron de 20\% en 1989 a 27.3\% en 2003; y además que las acciones contenciosas ha ganado legitimidad: 47.6\% en 2001 y 63\% en 2003 aprobaban el bloqueo de una carretera como forma de protesta, mientras en 2008, 36.8\% consideraba que la mejor manera de mostrar inconformidad es uniéndose a organizaciones sociales. Cfr. Segob. ENCUP 1989, 2001, 2003, 2008.

${ }^{3}$ El registro de conflictos varía según fuente y momento: Segob (2013) enumera 23 conflictos, la Red Observatorio de Conflictos Mineros en AL (2015) 40. Cfr. OCMAL s/f

${ }^{4} 2.137$ millones de hectáreas donde habitan 42 pueblos indígenas son explotadas por empresas mineras; "algunas concesiones abarcan casi la totalidad de los territorios de pueblos indígenas pequeños en población, como Cucapás, Pimas, Nahuas de Michoacán, Kakiapoo; mientras los más afectados por el tamaño del territorio concesionado son los Chatinos, Coras, Mixtecos, Tarahumaras, Tepehuanes y Zapotecos”. Segob 2013: 114

${ }^{5}$ En 12 de los 40 conflictos registrados han intervenido de manera violenta las fuerzas de seguridad del Estado en contra de los comuneros: intimidándolos, desalojándolos violentamente, amenazándoos y en uno de cada diez casos, asesinando a los comuneros de manera impune. Cfr. OCMAL.
} 
bienestar humano, la obtención de sustanciosas ganancias ${ }^{6}$ para las empresas.

En años recientes, además, hemos visto reiteradas movilizaciones masivas exigiendo la ampliación y recuperación de derechos políticos y civiles: elecciones limpias, respeto a la diversidad sexual, étnica, cultural, protección ambiental y particularmente, la defensa de los derechos humanos. En esta demanda se han incluido, en diversos momentos, liberación de presos políticos, alto a la represión, presentación de desaparecidos, supresión de grupos paramilitares y cese a la tortura; derecho a un juicio justo, cese de la desaparición forzada, de asesinatos extrajudiciales, de acoso y detenciones arbitrarias; eliminación del fuero a militar; respeto a la integridad física de las personas detenidas, es decir, eliminar cualquier forma de agresión física y verbal, política y sexual desde el momento en que entran en contacto con los agentes del Estado. Crecientemente, se subraya el derecho a comunicar, para frenar las agresiones contra periodistas y medios de comunicación independientes.

Esta gravedad explica que sean las organizaciones defensoras de derechos humanos las que de manera más persistente y sistemática se han creado y han desarrollado en la llamada transición mexicana (Maza Calviño 2009): desde el siglo XX, ante la urgencia de exigir la presentación de desaparecidos y la liberación de presos, nace el hoy denominado Comité Eureka, otros; otros se plantean la promoción de la cultura y la defensa de los derechos humanos (como la Academia Mexicana de Derechos Humanos, 1984, DECA-Equipo Pueblo). Muchos otros, formados desde entonces, se han ido consolidando como estructuras integradoras de proyectos emergentes, construyendo sistemas regionales, estatales y temáticos (educación, mujeres, pueblos indígenas, etc.). Hoy se agrupan en grandes organismos paraguas, como la Red Todos los Derechos para Todos (Red TDT) que reúne a 75 grupos con sede en 22 entidades federativas, vinculada con asociaciones civiles latinoamericanas y transcontinentales (Federación Latinoamericana de Asociaciones de Familiares de Detenidos-Desaparecidos (FEDEFAM), Amnistía Internacional (AI), etc.), superando las 300 (CODHEM 1997).

Este breve y apretado recuento da clara muestra de la multiplicación del activismo ciudadano que ha continuado buscando el respeto a sus derechos en la consecuente transformación del régimen en una democracia plena.

\section{LIBERALIZACIÓN LIMITADA Y VIOLACIÓN DE DERECHOS}

Concomitantemente, a pesar de que la expectativa era que a medida que avanzara la liberalización disminuiría la violencia, y se ampliarían los espacios de negociación y respeto de la legalidad establecida, la apertura política ha sido un proceso largo, tortuoso y limitado marcado por la resistencia al cambio (Olvera 2010,

\footnotetext{
${ }^{6}$ Tan solo con cuatro años de explotación de 56 mil hectáreas en Pino Alto Chihuahua, la Agnico-Eagles Mines Limited recibió utilidades brutas por 5,716.2 millones de pesos, y pagó solo un millón de pesos por derechos. Segob 2013: 99.
} 
Bizberg 2010). Se confirma en que las leyes emitidas son un retroceso frente a los acuerdos logrados en la negociación política: las reformas electorales (Gómez Tagle 1993), la Ley indígena (Alonso 2001) y la propia de derechos humanos (Treviño 2015) son ejemplos conspicuos. Lo mismo revelan las reformas que reducen claramente los derechos sociales y civiles (contracción de la responsabilidad social del Estado, criminalización de la acción colectiva, limitación de las leyes sobre transparencia, reforma educativa, etc.) y las normas que crean instituciones reguladoras sin los instrumentos necesarios para llevar a cabo los objetivos expresamente señalados (Comisión Nacional de los Derechos Humanos (CNDH), Procuraduría Federal de Protección al Ambiente (Profepa), Instituto Federal de Acceso a la Información y Protección de Datos (IFAI). Estos ejemplos, que abarcan los últimos 25 años, revelan que a pesar de la alternancia partidista hay continuidad en el ejercicio del poder. La liberalización política se ha truncado porque el pacto para la gobernabilidad enfatiza mantenerse al margen y a salvo del control ciudadano (Loaeza 2008, p. 121).

Un momento clave en este proceso ocurrió en 2006, durante la negociación en torno a la promulgación de la Ley para la Reforma del Estado (LPRE). Esta ley, firmada por unanimidad en ambas cámaras del Congreso, fue en realidad el pacto entre las dirigencias partidistas para "moderar" la competencia y lograr "acuerdos" interpartidistas y entre poderes. Las intenciones que se destacaron para aprobarla no mencionan en ningún momento las reformas necesarias para lograr un Estado democrático, fundado en un nuevo pacto social y político, sino expresamente: (1) la necesidad de lograr acuerdos entre poderes, (2) la de encauzar el conflicto político y (3) superar la falta de legitimidad y motivar a las fuerzas políticas partidistas a llegar a acuerdos ${ }^{7}$.

A pesar de ello, los cambios formales han sido constantes. Además de las numerosas reformas políticas, en el ámbito de los derechos humanos, el gobierno ha firmado cada uno de los nueve tratados internacionales que ha promovido la Organización de las Naciones Unidas (ONU), el Convenio 169 de la Organización Internacional del Trabajo (OIT) y los cinco instrumentos promovidos por el Sistema Interamericano; ha creado instituciones: la CNDH y diversas fiscalías: Fiscalía Especial para Movimientos Sociales y Políticos del Pasado (FEMOSPP), Fiscalía Especial para la. Atención de Delitos cometidos contra la. Libertad de Expresión (FEADLE), Fiscalía General de la República (FGR); y hecho numerosas reformas sustantivas a leyes, códigos, reglamentos, estatutos y artículos constitucionales sobre la materia, modificando tanto el ámbito federal como los estatales.

Sin embargo, la situación real de los derechos humanos en estas décadas no ha mejorado. La gravedad

\footnotetext{
${ }^{7}$ Cfr. Garabito 2007. Loaeza (2008: 121) coincide al afirmar que es el acuerdo interelitista (no la confrontación) lo que ha impedido el avance de la "democratización". Cansino (2012) anota que en 2012 se produjo una "regresión autoritaria pactada", que respondió a" cálculos políticos interesados mucho más poderosos" que un "efímero y poco rentable compromiso moral con la democracia”.
} 
del problema es patente en los despachos periodísticos cotidianos ${ }^{8}$, pero su crudeza se muestra contundente al analizar a detalle la información, que a pesar de la heterogeneidad de las fuentes y la carencia de sistematización, muestra un innegable incremento de las violaciones (Huber 2009)9.

La desaparición forzada se ha incrementado en la transición: si durante la Guerra Sucia (1972-1983) se registraron oficialmente 531 desapariciones (1,200 casos según organismos civiles), ya entre 1994 y 1997, 70 integrantes de organizaciones sociales "desaparecieron" tras ser detenidos, en presencia de testigos, por miembros de las fuerzas armadas y de las policías en el marco de operaciones de contrainsurgencia (AI 1999:13). Y en este siglo, la situación se agrava, pues incluso considerando que la cifra negra es de 85\%, los datos oficiales señalan 26 mil personas desaparecidas en seis años (diciembre 2006-junio 2013) (HRW 2014:2), agregándose 5 mil tan sólo en $2014^{10}$.

El delito de tortura presenta el mismo patrón de recrudecimiento. Si durante la década de la Guerra Sucia la CNDH reconoció 275 casos probados y 67 con indicios (CNDH 2001), en los noventa, el relator especial de la ONU reportó 45 casos probados que afectaban a 445 personas; pero a partir de 2005 las denuncias ante la CNDH crecen fenomenalmente: pasan de 330 en 2006 a 1161 en 2011; igual que las hechas ante el ministerio público militar que pasan de 182 en 2006 a 1491 en 2010 (HRW 2011). Independientemente de que las cifras reflejan también un aumento en la denuncia de hechos, es sintomático de la agudización del problema el que Amnistía Internacional (2001) afirme que: "La tortura a manos de funcionarios encargados de hacer cumplir la ley y de miembros de Ejército mexicano es una práctica que ha sido ampliamente denunciada y que ha sido reconocida por autoridades mexicanas, las Naciones Unidas, la CIDH y las organizaciones no gubernamentales mexicanas e internacionales" (Cit. por Álvarez Icaza, 2003).

Finalmente, los asesinatos extrajudiciales, que se han convertido en una práctica cotidiana ejercida no sólo por los grupos del crimen organizado, como era cotidiano, sino también por los cuerpos del Estado encargados de garantizar la seguridad en la sociedad, tal como lo han señalado reiteradamente las organizaciones defensoras de derechos humanos, nacionales e internacionales. Está documentado que en los casos del Ejido Morelia, Chis. (1992), Aguas Blancas, Gro. (1995), Acteal, Chis. (1997), El Bosque, Chis. (1998), El Charco, Gro.

\footnotetext{
${ }^{8}$ En septiembre de 2014, la desaparición de 43 estudiantes de la Normal Rural Rubén Isidro Burgos en Ayotzinapa Gro. causaba estupor, reforzado con el hallazgo casi cotidiano de fosas clandestinas (casi 500), donde se han localizado más de 4 mil víctimas (La Jornada, 14 de febrero de 2014, p. 5), halladas en 28 de las 32 entidades federativas del país. Concurrentemente, Juan Méndez, Relator Especial sobre Tortura de la ONU, al presentar su Informe sobre México señaló que la tortura, usada como medio de castigo y de investigación, está generalizada en México. (ONU 2015).

${ }^{9}$ Favela (2006) y Pansters (2012: 8-9) afirman que la violencia ha sido un factor mucho más presente en la historia política del régimen posrevolucionario mexicano de lo que la academia normalmente ha reconocido.

${ }^{10}$ El promedio anual de desapariciones, usando cifras oficiales, pasa de 53 (1973-83), a 24 (1994-1997), se dispara a 4,333 (20062013) y aumenta a 5,000 en 2014. (http://www.animalpolitico.com/2014/11/2014-el-ano-con-mas-casos-de-desaparicionesen-mexico-van-5-mil-98-victimas/)
} 
(1998), Tlatlaya, Mex. (2014), Iguala, Gro. (2014) y Tanhuato Mich. (2015), los cuerpos de seguridad del Estado, así como cuerpos paramilitares, han sido responsables directos o copartícipes.

A partir del año 2000 los asesinatos extrajudiciales, perpetrados por fuerzas del orden o por bandas criminales, se multiplican y se confunden, debido a la absoluta falta de investigación que deriva en una completa impunidad ${ }^{11}$. Javier Sicilia señala 80 mil muertos, Sanjuana Martínez recuenta 60 mil, el Semanario Zeta apunta 71,804 asesinatos asociados al narco y 109,142 homicidios dolosos que las autoridades reportan "sin datos", mientras que la PGR reconoce que entre diciembre de 2006 y septiembre de 2011, alrededor de 25 mil cuerpos sin identificar fueron a dar a la fosa común (Cfr. Centro Pro 2013).

\section{Los datos sobre ataques a los defensores de derechos humanos revelan una clara tendencia} al agravamiento de la situación:

\begin{tabular}{|c|c|c|c|c|c|c|}
\hline Tipo de Agresión & 2010 & 2011 & 2012 & 2013 & 2014 & 2015 (1 er. Sem.) \\
\hline Detenciones arbitrarias/ presos políticos & $245 / 18$ & $78 / 7$ & $292 /$ & $427 / 62$ & $323 / 56$ & $256 /$ \\
\hline Desapariciones forzadas & 2 & 30 & 6 & 23 & 48 & 4 \\
\hline Ejecuciones extrajudiciales & 15 & 17 & 11 & 20 & 19 & 8 \\
\hline Todo tipo de VDH registradas & n.d. & 353 & 156 & 274 & 488 & n.d. \\
\hline
\end{tabular}

Fonte: Datos tomados de los Informes anuales del Comité Cerezo 2010, 2011, 2012, 2013, 2014 y 2015.

Es evidente, entonces, que el incremento en la movilización ciudadana que reseñamos en la primera parte de esta sección, ha sido acompañado por un impactante agravamiento en la violación de los derechos humanos, al punto de parecer un país en guerra, como lo estableció el Alto Comisionado de la ONU para los Derechos Humanos, Zeid Ra’ad Al Hussein, con motivo de su visita a México, 7 de octubre de 2015:

Para un país que no se encuentra en medio de un conflicto, las cifras calculadas son, simplemente, impactantes: 151,233 personas asesinadas entre diciembre de 2006 y agosto de 2015, incluyendo miles de migrantes en tránsito. Desde 2007, hay al menos 26,000 personas cuyo paradero se desconoce.

Por otro lado, la importancia que la defensa de los derechos humanos, es decir, el derecho a la vida, ha adquirido dentro de la movilización social es reveladora de que la liberalización política es completamente insuficiente, pues está en peligro de persecución y de muerte cualquier ciudadano o ciudadana que denuncie abusos $^{12}$, o busque defender sus derechos o los de otros.

\section{LAS RAZONES DE LA VIOLENCIA DE ESTADO: NEOLIBERALISMO,}

\footnotetext{
${ }^{11}$ Como queda asentado en este informe de la ONU: el índice de impunidad para todo tipo de delitos es de 95\% y la ineficiencia judicial es muy alta, pues solo 10\% de los sumarios abiertos terminan en inculpación. ONU 2002: 31.

${ }^{12}$ PGR asienta que desde 2000, hay 102 periodistas asesinados, 18 desaparecidos y un número no posible de identificar de desplazados y/u obligados al exilio. Los asesinatos de periodistas se intensifican durante la presidencia de Calderón, pero en los
} 


\section{DESIGUALDAD EXTREMA Y CONCENTRACIÓN DEL PODER.}

Como lo han señalado numerosos trabajos, durante la fase actual del capitalismo globalizado, el control del aparato estatal tienen una importancia nodal para "mantener las condiciones de acumulación y competitividad en varias formas incluyendo subsidios directos y operaciones de rescate financiadas por los contribuyentes (México, los Tigres Asiáticos)". El capital "necesita al Estado para preservar la disciplina laboral y el orden social frente a la austeridad y la 'flexibilidad' y para acrecentar la movilidad de capital al tiempo que bloquea la movilidad de los trabajadores". En consecuencia, "el estado-nación ha adquirido nuevas funciones como un instrumento de la competencia. En todo caso, el estado-nación ese el agente principal de la globalización" (Meiksins 2010:81).

El evidente que la puesta en marcha de la estrategia neoliberal ha significado la transformación del sistema de regulación social y que el poder del Estado ha sido usado para "forzar los procesos de corporativización y privatización de activos previamente públicos, incluso contra la voluntad popular" (Harvey 2004: 115).

Cuando miramos la experiencia reciente de la economía mexicana encontramos continuidad en la aplicación de las políticas neoliberales, a pesar de la alternancia partidista en el Ejecutivo. Las políticas se han institucionalizado mediante reformas constitucionales que incluyen casi todos los ámbitos de la economía: apertura comercial ${ }^{13}$ y productiva, incluso en sectores antes considerados estratégicos, como minería ${ }^{14}$, electricidad ${ }^{15}$, petróleo ${ }^{16}$ y sistema financiero ${ }^{17}$; no obstante que estas políticas, no sólo han acrecentado la dependencia frente al mercado externo ${ }^{18}$ sino que han generado estancamiento ${ }^{19}$ y polarización ${ }^{20}$ del aparato

primeros nueve meses de 2014 se documentó una agresión cada 28 horas.
http://www.alainet.org/es/active/77429\#sthash.gaLZYqOd.dpuf

${ }^{13}$ A partir del Tratado de Libre Comercio de América del Norte, (TLCAN), el índice de apertura comercial pasó de 5\% a 40\% en 1993-2009 (Ayala et al, 2011: 510), y el índice del comercio exterior como porcentaje del PIB de 15 a más de 50, en 1980-2005 (Rodríguez A. 2009: 73), lo que a pesar de elevar las exportaciones no petroleras (del 35\% al 78\% de las totales en 1988-1998), no ha eliminado el déficit comercial que en 2008 era de 17 MMdD. (Inegi 2010: 7), haciendo a la economía menos competitiva: cayó del lugar 31 al 60 en 1999-2009. Cfr. Ayala et al, 2011:505)

${ }^{14}$ Bajo la nueva ley minera emitida en 1992 y reformada en 2005, 2006 y 2014 para profundizar la apertura al capital, entre 1993 y 2012 se otorgaron 43,675 concesiones mineras, que aumentaron en 644 títulos ( 1.6 millones de has) entre enero y junio de 2013. En total las concesiones abarcan 97.3 millones de has., equivalentes al 50\% del territorio nacional. Cfr. Dirección general de Inversión Extranjera (DGIE) 2014.

${ }^{15}$ Asociada al TLCAN, en 1992 se reformó la ley de energía eléctrica, para permitir inversión privada en la generación, y a partir de 2014, también en la conducción y distribución, pasando la Inversión Extranjera Directa (IED) de 15.2 Millones de Dólares (MdD) a 639 MdD entre 1994 y 2012. Cfr. Ángeles 2005; PcW 2014; DGIE. Fecha de consulta: 14/10/2014 10:53:39

${ }^{16}$ La esencia de la reforma energética es la casi irrestricta apertura a la inversión privada, con un régimen fiscal casuístico para asignaciones y contratos, contraprestaciones muy por debajo de la norma internacional y sin parámetros básicos para transparentar licitaciones y adjudicaciones. Le ley fomenta que los intereses corporativos controlen las entidades reguladoras. Cfr. Aguilera et al 2014: 136-7.

${ }^{17}$ El capital extranjero en la banca pasó de 5\% en 1994, a 52,4\% en 1996 y a 82\% en 2003. Cfr. Turrent 2007: 34-5.

${ }^{18}$ El sector más dinámico, el exportador, está altamente concentrado y dominado por capital foráneo: las 6 grandes exportadoras, 100\% extranjeras, generan 35\% de las exportaciones totales. Cfr. Arroyo 2003:173. 
productivo, y acentuado la precarización laboral y salarial ${ }^{21}$. La razón está en que estas transformaciones, rematadas con el manejo de la política fiscal ${ }^{22}$, han favorecido a los sectores económicamente más poderosos, en desmedro de la mayoría de la población ${ }^{23}$.

Complementariamente, la privatización de bienes y empresas públicas, que ha sido un elemento central de la política de liberalización económica, ha servido también para facilitar la consolidación de los grandes capitales y para formar lazos perdurables entre las élites corporativas, nacionales y extranjeras y los funcionarios clave en la administración estatal (Salas-Porras, 2014:297) 24. De tal modo, la reducción del sector público de la economía no ha significado sólo la liquidación de entidades públicas, sino la transferencia de cuantiosos recursos a agentes privados ${ }^{25}$, mediante operaciones frecuentemente poco transparentes y con indicios diversos de que mediante la subvaluación de los activos vendidos o mediante variadas operaciones de rescate y recompra, los

\footnotetext{
${ }^{19}$ En los últimos 25 años la economía se ha vuelto más dependiente de las importaciones, acentuando el desequilibrio en el sector externo y "limitando la capacidad de crecimiento, pues con recursos externos similares a los que recibía en los años 1950-1980, ahora crece a un tercio de las tasas a las que crecía entonces" (Moreno et al, 2005:14)

${ }^{20}$ La destrucción de las firmas medianas ha polarizado la estructura productiva, pues pocas empresas enormes, vinculadas al capital transnacional, operan rodeadas de una miríada de pseudo empresas: en 2009, 90\% operaban con menos de 5 personas y 65\% tenían dos puestos de trabajo o menos!; mientras las grandes (más de 251 ocupados) son apenas el 0.19\% de los establecimientos; $47 \%$ del total se dedican al comercio minorista y $12 \%$ a la manufactura. (Inegi 2015a).

${ }^{21}$ Las políticas de "adelgazamiento del Estado, control salarial, reformas al sistema de seguridad social y la flexibilización de las relaciones laborales contribuyeron a la precariedad del empleo y a deprimir el nivel general de los salarios". (Puyana y Romero 2004: 294). Entre los estudiosos hay consenso en torno a que la lógica de las empresas para hacer frente a la competencia global se basa en la extenuación salarial: "no se está frente a un problema de baja competitividad y productividad, sino ante una estrategia empresarial sustentada en la explotación [extrema] de la fuerza laboral”. (De Oliveira y Mora-Salas 2009: 224; Aguayo y Salas 2002; Arroyo 2003; Carrillo y Gomis 2011).

${ }^{22}$ La política fiscal regresiva está orientada a gravar el consumo, más que el ingreso y la riqueza acumulada: en promedio la Organización para la Cooperación y el Desarrollo Económicos (OCDE) recibe 32\% de sus ingresos fiscales de impuestos indirectos, México el 54\%. La tasa marginal del ISR es la más baja de la OCDE (32\% contra 50\%) y los ingresos por dividendos más los impuestos empresariales y personales en conjunto dan 30\%, cuando en la OCDE es de $42 \%$. Hasta 2014 tampoco se grababan las operaciones en la Bolsa, y aún hoy disfrutan de múltiples exenciones, y las herencias siguen exentas. Quien tiene es quien más beneficios fiscales recibe. (Esquivel 2015:21-22) Hasta 2013 México era uno de los pocos países donde no se cobraba ningún impuesto a la producción a boca de mina. A pesar de que en 2014 se instauró $7.5 \%$ por impuesto a la explotación minera, las gestiones de la Cámara Minera de México (CAMIMEX), que en 2011 informó a sus agremiados que logró una "coordinación con la Comisión de Enlace Legislativo para que finalmente se evitara que se estableciera un derecho a la producción minera", siguen siendo exitosas, pues el impuesto es apenas una cuarta parte del que cobran otros Estados latinoamericanos. (González 2011: 5-7, 39 y 25; Segob 2013: 106 yss).

${ }^{23}$ La distribución de la riqueza entre los factores de la producción en los últimos 30 años (1981-2012), ha castigado al trabajo y favorecido al capital: la parte de éste crece de 62\% a 73\%, y la del primero cae de 38\% a 27\%. (Esquivel 2015:14).

${ }^{24} 22$ funcionarios clave han transformado la relación entre el Estado y las empresas, orquestando negociaciones con las élites corporativas, nacionales y extranjeras, creando compañías consultoras asociadas con firmas globales de ingeniería financiera, y circulando de puestos públicos a posiciones privadas y viceversa. Salas-Porras 2014: 297

${ }^{25}$ Sidermex fue saneada financieramente y luego prácticamente regalada, pues su capital contable era de $6 \mathrm{MMdD}$ y se vendió en $750 \mathrm{MdD}$. Por los ingenios azucareros se recibieron $325 \mathrm{MdD}$ y a su posterior rescate se destinaron $460 \mathrm{MdD}$. Por la venta de los bancos se obtuvieron $12 \mathrm{MMdD}$ y en el rescate bancario se han gasta 98.8 MMdD. (Sacristán 2006:56-58; Hernández O. 2001:200). Los ingresos por privatizaciones entre 1982 y 2001 sumaron $32 \mathrm{MMdD}$, equivalente al 29\% de los $110 \mathrm{MMdD}$ a que asciende la deuda pública contraída para el rescate de la banca, las autopistas concesionadas, las aerolíneas y los ingenios. http://www.gestiopolis.com/privatizaciones-en-mexico
} 
grandes capitales han sido fortalecidos ${ }^{26}$.

Este proceso ha tenido como contraparte la polarización social, resultado de la concentración de la riqueza y la agudización de la desigualdad extrema. Los datos más recientes disponibles (2008-2012) señalan que México tiene una desigualdad social muy alta: su coeficiente de Gini es 0.441 , cuando el promedio es de $0.373^{27}$, por lo que ocupa el lugar 25 entre los más desiguales, es decir, muestra una desigualdad mayor al 80\% de los 132 países de la muestra (Esquivel 2015: 13). Esta situación resulta de la altísima concentración del ingreso en el decil más rico, que controla el 64\% del total de la riqueza del país, dentro del cual el percentil más alto retiene 21\% del ingreso total nacional (muy por encima del 10\% que presenta el promedio de la muestra). El problema es más agudo aún, pues su evolución muestra una tendencia al agravamiento. Según datos de Wealthinsight (2013) en 2012 había en México 145 mil individuos que concentraban ese año el 43\% de la riqueza nacional, superando por mucho el promedio que corresponde a los millonarios en otras naciones, quienes concentran apenas el 29\% de los recursos de sus respectivos países. (Esquivel 2015:16). La apertura comercial y la privatización acentuaron la tendencia, pues ente 1996 y 2004 la fortuna promedio de cada miembro del grupo de 16 mexicanos multimillonarios pasó de 1.7 a $8.9 \mathrm{MMdD}$, de modo que entre 2002 y 2014 su riqueza paso del $2 \%$ al $9 \%$ del PIB nacional.

Así, la política neoliberal ha concentrado el poder de las élites económicas en México, y lo potencian mediante la creación de redes. Los 48 integrantes de la organización cupular, Consejo Mexicano de Hombres de Negocios (CMHN), mediante el "entrecruzamiento corporativo" tienen influencia sobre el 80\% de las empresas que cotizan en la BMV y mediante ello controlaban, en 2009, el 27\% del PIB. (Cokelet 2013: 28-9). Esta organización empresarial de élite, desde su fundación en 1962 tiene acceso exclusivo a información asimétrica a través de su contacto regular y directo con el Ejecutivo federal, mediante reuniones con los candidatos presidenciales, desayunos con funcionarios públicos, el manejo de su compromiso de inversión anual (normalmente entre 10 y $15 \%$ de la inversión privada total) y las reuniones mensuales con el Presidente.

La influencia del CMHN se extiende a otras organizaciones cupulares que han contribuido a conformar, como el Consejo Coordinador Empresarial (CCE) y la Coordinación de Organismos Empresariales para el Comercio Exterior (COECE), así como a las asociaciones empresariales transnacionales como son el Grupo

\footnotetext{
${ }^{26}$ De la 1155 entidades públicas existentes en 1982, en julio de 1999 quedaban 203. La venta de siderúrgicas, aerolíneas, mineras, telefónica y banca, entre otras, favoreció a los grupos empresariales más poderosos: Carso, Visa, Vitro, Minera México, Alfa, que fueron los que concentraron el grueso de las privatizaciones. A dicha transferencia se debe en buena medida que sus dueños y directivos hayan acrecentado sus riquezas de modo súbito: si en 1988 en la lista de Forbes solo estaba la familia Garza Sada, en 1994 la lista incluía 24 nombres nuevos, varios de los cuales están en la lista de los beneficiarios de las privatizaciones: Carlos Slim, Jorge Larrea, Alberto Bailleres, Ricardo Salinas Pliego, Adrián Sada González, Roberto Hernández, Eugenio Garza Lagüera, Alfredo Harp Helú (Hernández O 2001:170 y 183)
} 
Columbus de América Latina y la Business Roundtable de Estados Unidos, con los que tiene una sociedad estratégica y permanente. Los analistas aducen el quid pro quo entre empresas y gobierno, en el que a cambio de recibir información para hacer negocios, los potentados otorgan apoyo y legitimidad a la clase política (Cokelet 2013).

La contraparte de este escenario la sintetiza Del Castillo (2013:77-78) al afirmar que 51 millones de personas (44\% de la población) tiene algún grado de carencia alimentaria y 27 millones de mexicanos tienen hambre $\left(23 \%\right.$ de la población nacional) ${ }^{28}$. Ello resulta de la pérdida de empleos ${ }^{29}$, la baja calidad de los que existen $^{30}$, y la pauperización salarial ${ }^{31}$.

En este contexto de estancamiento económico y desigualdad extrema, crece la importancia del crimen organizado, y del narcotráfico en particular. La literatura sobre el tema es muy abundante, sin pretender abarcarla, simplemente queremos traer a la discusión el tema en dos de sus vertientes: la relación entre desigualdad y delincuencia, por un lado, y la relación entre crimen organizado y aparato estatal. En lo que hace a la primera, Salama (2003:188; 195-6) señala que si bien la pobreza por sí misma no está asociada a la violencia, sí lo está cuando se intensifica y se acentúan la desigualdad y la concentración de la riqueza, por la profunda impresión de injusticia que generan, una injusticia que no se puede resolver recurriendo a un Estado sometido a las restricciones neoliberales. Solís (2013: 16 y 18), por su parte, señala que frente a la profundización de la crisis, no es de extrañar que sectores cada vez más importantes de la población vean en la economía ligada a la droga una alternativa para obtener una fuente de ingresos que les permita acceder a mejores condiciones de vida, que además, dado el crecimiento de la informalidad, se hace más asequible: informalidad y crimen organizado muestran un crecimiento exponencial contiguo.

En lo que toca a la segunda, la información revela que la economía del crimen organizado alcanza

\footnotetext{
${ }^{27}$ Del Castillo (2014: 64) afirma que con datos de la Encuesta Nacional de Inclusión Financiera 2012 se revela que el 10\% de las familias más ricas suma el 59\% del ingreso corriente total y el 64\% del ingreso de mercado.

${ }^{28}$ La encuesta revela que por falta de recursos el 35.6\% de los hogares de México tuvo una alimentación muy poco variada; en $24.8 \%$ algún adulto comió menos de lo que debía; en 15.7\% dejaron de hacer una comida, y en 14.2\% es decir, en poco más de 4.4 millones de hogares, se quedaron en algún momento sin comida (Del Castillo 2013: 75)

${ }^{29}$ En 2003 había 9.1\% menos empleos que antes de 1994 (Arroyo 2003:187) y en 2011 había 1.5 millones más desempleados que en 2000 (Ruíz y Ordaz 2011: 93). Desde 2000 se han creado apenas 600 mil plazas anuales, mientras la población crece un millón al año, pasando los desempleados de 4.7 millones en 2000 a 8.2 millones en 2009. Inegi 2015 b.

${ }^{30}$ En el sector informal está casi 30\% de los empleos, es decir, 13 millones, 44\% más que en 1995 (Nápoles y Ordaz 2011, p. 101), $40 \%$ de ellos creados por micro empresas. Pero en las grandes empresas los nuevos puestos también son "precarios", por ello el 60\% de la fuerza laboral (12.5 millones de personas) carecen de seguridad social, empleo permanente, contrato laboral y de cualquier tipo de prestación social.

${ }^{31}$ El salario mínimo es el octavo más bajo del mundo. Equivale al 25\% del de 1976, por debajo del doble de la línea de pobreza extrema. En 2009, 6 millones de trabajadores recibieron menos de 1 salario mínimo; 10 millones, menos de 2 salarios mínimos y 9 millones menos de 3 salarios mínimos; además de casi 4 millones de ocupados sin ingresos, que resultan en que 55\% de los trabajadores reciben un salario por debajo de la línea de pobreza. (Esquivel 2015, Chávez 2014, Goche 2014, Merino y Fierro 2014)
} 
dimensiones tales que sus dividendos (en México produce ganancias anuales de entre 25 y $30 \mathrm{MMdD}$, alrededor del 2-3\% del PIB, Morris 2013) no pueden realizarse si no circulan a través de los canales de la economía formal y sus actividades no serían posibles sin la participación (anuencia o incluso dirección) de las estructuras estatales encargadas de combatirlos ${ }^{32}$. El hecho es que en las dos últimas décadas el número de organizaciones delictivas creció de manera exorbitante, hoy se habla de nueve grandes cárteles, presentes en 500 localidades del país (Morris 2013), y con la concomitante presencia de fuerzas de seguridad (policías de toda laya, Armada y Ejército), se genera un escenario donde las violaciones a los derechos humanos se multiplican.

Concurrentemente, la manipulación del temor ciudadano a la inseguridad y la necesidad del combate a la delincuencia han sido empleados como artilugios para justificar el empleo de la fuerza contra los grupos movilizados, haciéndolos aparecer como delincuentes. En este contexto se ha producido la equiparación de las acciones contenciosas tradicionales de la movilización social, con acciones delincuenciales, generando un proceso de "judicialización" del tratamiento de la protesta, como apuntamos arriba, que sirve de pantalla para llevar a cabo una política claramente represiva de la acción colectiva. Así, en los códigos penales se han tipificado como delitos conductas que antes no eran consideradas como tales, y se han elevado desmesuradamente las penas y castigos asociados a su realización ${ }^{33}$. Esta operación jurídica, que desvirtúa la naturaleza de la acción colectiva y la sanciona con penas desmesuradas, está orientada a desincentivar su empleo, revelando la debilidad que tienen las libertades civiles en la sociedad mexicana contemporánea. (Favela 2010; Correas 2011).

\section{A MANERA DE CONCLUSIÓN}

La crisis de los derechos humanos que experimenta México es un fenómeno que urge comprender, explicar y desentrañar, para poder resolverlo. La gravedad de los hechos que ocurren en el territorio nacional cotidianamente no debe ser "naturalizada", ni asumida como un destino inalterable. Por ello es necesario que indaguemos sobre sus raíces, que comprendamos los mecanismos institucionales, las prácticas políticas y sociales, los factores económicos y culturales que la generan, para que eventualmente podamos superarla y avanzar en la

\footnotetext{
32 El señalamiento sobre esta relación es unánime, aunque con variaciones: para algunas interpretaciones se trata de eventos puntuales y acotados donde las autoridades otorgan protección de manera forzada (el "plomo o plata" de las versiones oficiales); otras lo miran como resultado de la corrupción, ya sea puntual y esporádica (Astorga y Sirk 2010), o bien efecto de una definitiva penetración del aparato estatal por parte de la delincuencia (tesis del Estado Narco, Solís 2002). Finalmente, otra interpretación la mira como una relación estructural, en la que desde los niveles más altos del aparato estatal se dispone la venta de protección a los grupos criminales a cambio de cuotas sobre las utilidades que su acción genera (tesis del Crimen Organizado de Estado, Resa 1999 y 2015).

${ }^{33}$ Así ha ocurrido con la retención de personal, la ocupación de edificios públicos y el bloqueo de carreteras, que han sido tipificados como delitos. El Frente por la Libertad de Expresión y la Protesta Social en México, formado por más 80 organizaciones, presentó en octubre de 2014 ante la Comisión Interamericana de Derecho Humanos el informe "Derechos Humanos y Protesta en México", detallando el análisis de las leyes "anti-protesta".
} 
construcción de la democracia.

Las ideas presentadas arrojan luz sobre la importancia de dos factores que forman parte del entramado que sostiene esta masiva violación de los derechos humanos y que no han sido debidamente considerados por la literatura del campo. La creciente movilización de sectores populares, motivada por la transición incompleta y por la necesidad de recuperar los recursos y derechos que el neoliberalismo les arranca, enfrenta, una respuesta violenta por parte de una elite estatal comprometida con la continuación de una estrategia económica que genera estancamiento, aguda concentración de la riqueza, desigualdad extrema y mayor conflictividad social.

El otro factor que subrayamos, claramente entrelazado con el anterior, es el neoliberalismo y la importancia que tiene el aparato estatal en su implementación. La marcha de la globalización exige a las empresas fincar sus posibilidades de competencia en la reducción de los costos y la ampliación de sus escalas de operación: eso es precisamente lo que está detrás del proceso de concentración de los recursos en manos de las empresas más grandes, y de la pulverización de las medianas y pequeñas al punto de convertir la economía en un mar de pseudo empresas, controlado y dirigido por un puñado de grandes consorcios, que por otro lado, no han garantizado ni el crecimiento del producto, ni el del empleo, ni la estabilidad macroeconómica.. Acumular recursos de cualquier manera, sea el despojo, la precarización laboral y/o el uso indebido del gasto público, es lo que la lógica de la reproducción capitalista impone: la competencia globalizada torna más despiadada la conducta de las empresas, para lo cual, como referimos al inicio recurre a un uso más directo del poder del Estado. (Meiksins 2000)

Actualmente, las facultades reguladoras del Estado están orientadas, contrariamente a lo que ocurría en la etapa fordista, a facilitar la concentración y la centralización de los recursos en los agentes económicos más poderosos, mediante todo el conjunto de políticas neoliberales: liberalización comercial, productiva y financiera, contención salarial, flexibilización laboral, privatización de bienes y empresas públicas, política fiscal regresiva, y reducción del gasto social al tiempo que se emplean cuantiosos recursos en el rescate de empresas privadas. Para llevar a cabo este proceso de transformación estructural es esencial el control del aparato estatal, pues no sólo es desde allí que se promulgan, instauran y legitiman los cambios, sino que además se controlan los medios para garantizar que la resistencia social a esta dinámica de despojo masivo por un lado, y enriquecimiento súbito y desmedido de una minoría por el otro, pueda avanzar y tener éxito. Como bien lo muestra el caso mexicano, donde la continuidad en las políticas aplicadas por el grupo en el poder, a pesar de la alternancia partidista, nos deja ver claramente quienes son los beneficiarios de las reformas, arroja luz sobre las razones que están detrás de las dinámicas que fomentan la impune violación de los derechos humanos en el país.

Este artículo es exploratorio, sin embargo, trata de introducir algunos pensamientos y posibilidades novedosas en la comprensión de la crisis de los derechos humanos. Confío en que ayude a identificar los problemas y sea una contribución para pensar posibles soluciones a la acerba situación que vive México. 


\title{
NEOLIBERALISM AND CITIZEN MOBILIZATION: TWO LINKS LOST IN THE UNDERSTANDING OF THE CRISIS OF HUMAN RIGHTS IN MEXICO
}

\begin{abstract}
This essay aims to examine the human rights crisis that affects Mexican society, recovering the importance of two factors ignored by the literature of the countryside: the incidence of neoliberal strategy and the increase of social mobilization. The human rights situation in regimes in transition and under the impact of policies of openness and privatization deteriorate as political elites face the challenge of social mobilization through repression. Concurrently, stagnation, polarization, concentration of wealth, and organized crime play a central role in this explanation of the human rights crisis in contemporary Mexico.
\end{abstract}

Keywords: Human Rights, Social Mobilization, Democratic Transition, State Violence.

\section{BIBLIOGRAFÍA CITADA}

AGUAYO, Fy C. Salas. 2002. Reestructuración y dinámica del empleo en México, 1980-1998. Región y Sociedad $14,(25): 3-62$.

AGUILERA, M, et. al. 2014. Consideraciones sobre la reforma de la industria petrolera en México. En.: Economía UNAM (Journal of Economic Literature) 11, (33): 110-137.

ÁLVAREZ, E. 2003. La experiencia de la CDHDF en materia de tortura. En.: Asatashvili, M. et al. (Ed) El caso de la tortura en México. Seminario internacional sobre estadísticas e indicadores para el diagnóstico nacional en materia de derechos humanos 173-79. México: $\mathrm{CNDH}$.

AMNISTÍA INTERNACIONAL. 1999. México. Bajo la sombra de la impunidad. Madrid: Grupo Nikzor//Amnistía Internacional.

ÁNGELES, S. 2005. Resultados del TLCAN en el sector energético. En.: Witker, J. (Coord.) El Tratado de Libre Comercio de América del Norte. Evaluación Jurídica: diez años después. (263-90). México: UNAM.

ARROYO, A. 2003. Promesas y realidades: el Tratado de Libre Comercio de América del Norte en su noveno año. Revista Venezolana De Economía y Ciencias Sociales 9, (2): 167-95.

ASTORGA, L y Shirk, D A. 2010. Drug Trafficking Organizations and Counter-Drug Strategies in the U.S.Mexican Context. UC San Diego: Center for U.S.-Mexican Studies.

AYALA, AV, et al. 2011. Determinación de la competitividad del sector agropecuario en México 1980-2009. Revista Mexicana De Ciencias Agrícolas 2, (4): 501-14.

CANSINO, C. 2012. De la transición continua a la instauración democrática fallida. El caso de México en perspectiva comparada. Http:// politicaparaciudadanos.blogspot.mx/2012/08/de-la-transicion-continua-la.html. (Consultado 22 junio 2015). 
CARRILLO, J y R Gomis. 2011 . Un estudio sobre prácticas de empleo en firmas multinacionales en México: un primer mapeo. Frontera Norte 23, (46): 35-59.

CASTILLO, G. 14 2014. En ocho años se han localizado 400 fosas clandestinas con más de 4 mil víctimas. La Jornada, p. 5.

DEL CASTILLO, M. 2013. El hambre en México. Estudios 11, (107): 71-111. 2014. Thomas Piketty para México. Estudios 12, (110):35-68.

MIGUEL AGUSTIIN PRO JUÁREZ, A. C. 2012. Han destruido la vida de este lugar: megaproyectos, violaciones a derechos humanos y daños ambientales en México. México: Centro Pro Juárez, A.C.

CNDH. 2001. Recomendación 026/2001.

CODHEM. 1997. Directorio de Organismos Defensores de Derechos Humanos en México. Resumido del Directorio de Organismos de Derechos Humanos. CNDH. Derechos Humanos 5, (28): 166-203.

COKELET, B. 2013. El Consejo Mexicano de Hombres de Negocios: La política de negocios, las élites y la toma de decisiones en México. Maestría en Ciencias Políticas y Negocios Internacionales: Universidad de Nueva York (NYU).

CORREAS, O. 2011. La criminalización de la protesta social en México. México: CeIICH-Coyoacán.

CHÁVEZ, M. 2014. Salario mínimo y salario medio de México: entre los peores del mundo. Contralínea, 8 octubre 2014. http://contralinea.info/archivorevista/index.php/2014/10/08/salario-minimo-salario-medio-demexico-entre-los-peores-del-mundo/ (consultado 10 de enero de 2015)

DAVENPORT, Ch. y D. Armstrong. 2004. Democracy and the violation of HR: A statistical Analysis from 1976 to 1996. Midwest Political Science Association 48, (3): 538-54.

DGIE. Dirección General de Inversión Extranjera. 2014. Inversión Extranjera Directa en México y en el Mundo. Carpeta de Información Estadística. Secretaría de Economía. http://www.economia.gob.mx/files/comunidad_negocios/ied/analisis_publicaciones/Otros\%20estudios/car peta_informacion_estadistica_0414.pdf(consultado 9 octubre 2014)

EISINGER, P. 1973. The Conditions of Protest Behavior in American Cities. American Political Science Review 67, (1): 11-28.

ESPINOZA, R y A Barreda. 2012. La destrucción de México ante el Tribunal Permanente de los Pueblos. El Cotidiano, (172): 167-82.

ESQUIVEL, G. 2015. Desigualdad extrema en México. Concentración del poder económico y político. México: OXFAM.

ESTÉVEZ, A. 2010. Los derechos humanos en la sociología política contemporánea. En.: A Estévez, y D Vázquez (Coord.), Los derechos humanos en las ciencias sociales: una perspectiva multidisciplinaria 135-65. México: 


\section{FLACSO-CISAN.}

FAVELA, M. 2006. Protesta y Reforma en México, 1946-1994: Interacción entre estado y sociedad. México: CeIICH-UNAM-Plaza y Valdés

2010. Ampliación de la ciudadanía y criminalización de la protesta: negación de derechos políticos y reducción del estado de derecho. En..J Gandarilla, J Juárez, y R Mendoza (Ed), Jornadas Anuales de Investigación 2009.35-44. México: CeIICH.

2010a. Sistema político y protesta social: del autoritarismo a la pluralidad. En.: Bizberg, I y Zapata, F

(Coord.) Los Grandes Problemas de México. VI. Movimientos sociales. México: El Colegio de México; 2010: 101-145.

FEIN, H. 1995. More murder in the middle: Life integrity violations and democracy in the World, 1987. Human Rights Quarterly 17,(1): 170-191.

FRENTE POR LA LIBERTAD DE EXPRESIÓN Y LA PROTESTA SOCIAL EN MÉXICO. 2014. Derechos Humanos y Protesta en México, Informe ante la Comisión Interamericana de Derecho Humanos.

GARABITO, R. 2007. Ley para la Reforma del Estado y transición a la democracia (una visión escéptica). El Cotidiano, (144): 38-48.

GOCHE, F. 2014. De 15 mil pesos, déficit del salario mínimo. Contralínea 19 de Agosto de 2014. http:/contralinea.info/archivo-revista/index.php/2014/08/19/de-15-mil-pesos-deficit-del-salario-minimo/:

Contralínea. (consultado el 20 de noviembre de 2015)

GONZÁLEZ R, J J. 2011. Minería en México. Referencias generales, régimen fiscal, concesiones y propuestas legislativas. Centro de Estudios Sociales y de Opinión Pública, 52. Centro de Estudios Sociales y de Opinión Pública.

HARVEY, D. 2005. El nuevo imperialismo: acumulación por desposesión. Socialist Register, (2004): 99-129.

HERNÁNDEZ O., RC. 2001. Globalización y privatización: el sector público en México, 1982-1999. México: INAP, AC.

HUBER, R. 2009. La política de derechos humanos en México: Balance de la última década. México: Fundación Konrad Adenauer.

HUMAN RIGHTS WATCH. 2014. Informe Mundial. Resumen de país, Human Rights Watch. 2011. Ni seguridad, ni derechos. Ejecuciones, desapariciones y tortura en la guerra contra el narcotráfico de México. Human Rights Watch.

INEGI. 2010. Estadísticas económicas. Balanza comercial de México. México: INEGI. 2015a. Censos Económicos 1999, 2004, 2009.

2015b. ENOE. Encuesta Nacional de Ocupación y Empleo. Indicadores Estratégicos. http://www.inegi.org.mx/sistemas/bie/. (Consultado el 22 de agosto de 2015)

KING, J C. 1998. Repression, domestic threat, and interactions in Argentina and Chile. Journal of Political and Military Sociology 26, (2): 191-211. 
LOAEZA, S. 2008. Entre lo posible y lo probable. La experiencia de la transición en México. México: Planeta.

MAZA C., E C. 2009. Derechos humanos. México: retórica sin compromiso. México: Flacso.

MEIKSINS W., E. 2000. Trabajo, clase y estado en el capitalismo global. Revista Del Observatorio Social De América Latina (1): 111-18.

MERINO, J. y E. Fierro. 2014. Salario mínimo: México contra el mundo. Animal Político. 14 de agosto de 2014. http://www.animalpolitico.com/blogueros-salir-de-dudas/2014/08/14/salario (consultado el 28 de octubre de 2015)

MORENO, J.C. et al. 2005. La economía mexicana después del TLCAN. Revista Galega De Economía 14, (1-2): $1-20$.

MORRIS, S. 2013. Drug trafficking, corruption and violence in Mexico: mapping the linkages. Trend in Organized Crime 16, (2): 195-220.

OCMAL. Observatorio de Conflictos Mineros en AL. Base de datos sobre conflictos mineros. http://www.conflictosmineros.net/. (Consultado el 5 de febrero de 2015)

OLIVEIRA, O de y M Mora-Salas. 2009. La degradación del empleo asalariado en los albores del siglo XXI: Costa Rica y México. Papeles De Población 15, (61): 195-231.

ONU. 2015. Relator especial alerta de tortura, malos tratos e impunidad en México. http://www.un.org/spanish/News/story.asp?NewsID=31848\# (consultado el 9 de marzo de 2015)

ONU. Comisión de Derechos Humanos. 2002. Informe presentado de conformidad con la resolución 2001/39 de la Comisión de Derechos Humanos. Los derechos civiles y políticos en particular las cuestiones relacionadas con: la independencia del poder judicial, la administración de justicia y la impunidad, Relator Especial sobre la independencia de los magistrados y abogados Dato'Param Coomarawamy. E/CN.4/2002/72/Add.1. ONU, Nueva York.

PANSTERS, W (Ed.) 2012. Violence, Coercion and State-Making in Twentieth Century Mexico. Stanford California: Stanford University Press.

PUYANA, A y J Romero. 2004. Apertura comercial y remuneraciones a los factores: la experiencia mexicana. Estudios Económicos 19, (2): 285-323.

REAGAN, P y E Henderson. 2002. Democracy, threats and political repression in developing countries: are democracies internally less violent? Third World Quarterly, 23 (1): 1-31.

RESA, C. 1999. Sistema político y delincuencia organizada en México: el caso de los traficantes de drogas. IU Gutiérrez Mellado Working Paper 02/99: 42 pp.

RODRÍGUEZ A., A. 2009. Apertura comercial, balanza comercial e inversión extranjera directa en México, 19802006. Investigación Económica 68, (269): 73-111. 
RODRÍGUEZ N., S. 2001. Texcoco, la resistencia que no cesa. Proceso (1308), 25 noviembre 2001: 54-58

ROMO, P. 2008. Criminalización de la protesta. Serapaz, México.

RUIZ N., P y J.L. Ordaz D. 2011 . Evolución reciente del empleo y el desempleo en México. Journal of Economic Literature 8, (23): 91-105.

SACRISTÁN R., A. 2006. Las privatizaciones en México. Economía Unam 3 (9): 54-64.

SALAMA, P. 2003. La violencia latinoamericana vista por los economistas. Cuadernos De Economía 22, (38): 179-98.

SALAS-PORRAS, A. 2014. Las élites neoliberales en México: ¿Cómo se construye un campo de poder que transforman las prácticas sociales de las élites políticas? Revista Mexicana De Ciencias Políticas y Sociales 59, (222): 279-312.

SEGOB. ENCUP. Encuesta Nacional sobre Cultura Política y Prácticas Ciudadanas. 1989, 2001, 2003, 2008. http://www.encup.gob.mx/en/Encup/Principales_resultados

SEGOB. Comisión para el Diálogo con los Pueblos Indígenas. 2013. Estudio de la minería en México. Un análisis comparado con Canadá. México: SEGOB. http://www.cdpim.gob.mx/v4/pdf/e_minero.pdf

SERAPAZ, A. C. Observatorio de la Conflictividad Social Servicio y Asesoría para la Paz. 2007. Informe de la conflictividad social en México, enero-diciembre 2006, Serapaz, A. C.

SOLÍS G., J.L. 2013. Neoliberalismo y crimen organizado en México: el surgimiento del Estado narco. Frontera Norte 25, (50): 7-34.

TURRENT, E. 2007. Historia sintética de la banca en México. México: Banco de México.

Trabalho enviado em 15 de setembro de 2016.

Aceito em 03 de novembro de 2016. 